\title{
Application of a Fast Isoprene Sensor (FIS) for measuring isoprene production from marine samples
}

\author{
Dan A. Exton1, David J. Smith', Terry J. McGenity', Michael Steinke', Alan J. Hills ${ }^{2}$, and David J. Suggett ${ }^{\text {* }}$ \\ ${ }^{1}$ Department of Biological Sciences, University of Essex, Colchester, Essex, UK, CO4 3SQ \\ ${ }^{2}$ National Center for Atmospheric Research, Boulder, Colorado 80307-3000
}

\begin{abstract}
Research into isoprene production from marine sources traditionally relies on gas chromatography techniques which are labor intensive, provide a slow sample turnover, and require significant method training. An alternative method is the use of a Fast Isoprene Sensor (FIS), a chemiluminescence-based approach that provides real time isoprene analysis, but is relatively simple to run and also portable. Until now, the FIS has been used in terrestrial but not aquatic isoprene studies. Due to the added difficulties with marine compared with terrestrial sampling, particularly potential interference from dimethyl sulfide (DMS), we have developed a new protocol that allows accurate and reliable data to be obtained from FIS analysis. The detection limit of our modified system to standard gas was $0.02 \mathrm{nM}(0.5 \mathrm{ppbv})$, while minimum isoprene production detected by the FIS was $0.59 \mathrm{nmol} \mathrm{h}^{-1}$ (for Thalassiosira weissflogii). We also compared our FIS-based approach with GC analysis of isoprene emission from marine samples of micro- and macro-algae, and demonstrated a strong similarity $\left(r^{2}=\right.$ 0.910, slope $=1.003$ ). The ability to use FIS analysis with marine samples will significantly broaden the scope of isoprene research in marine environments, permitting remote field work, and allow previously unanswered questions to be addressed.
\end{abstract}

Biogenic production of volatile organic compounds (VOCs) by marine organisms has been an active area of research for the last two decades (Baker et al. 2000; Fink 2007). These VOCs, which include dimethyl sulfide (DMS) and short-chain hydrocarbons (Fink 2007), are well recognized in playing important roles including regulation of local climate (Stefels et al. 2007) and may affect trophic interactions (Steinke et al. 2002). To date, most attention in marine environments has focused on DMS and its precursor dimethylsulfoniopropionate (DMSP) (Bates et al. 1987; Charlson et al. 1987; Stefels et al. 2007; Turner et al. 1996) since DMS has a large atmospheric flux (15-33 $\mathrm{Tg} \mathrm{S} \mathrm{yr}^{-1}$ ) (Kettle and Andreae 2000), a vital role in cloud condensation nuclei formation (Charlson et al. 1987; Vallina and Simó 2007), and an ecological function in infochemistry (Fink 2007; Steinke et al. 2006) and tolerance to

*Corresponding author: E-mail: dsuggett@essex.ac.uk

\section{Acknowledgments}

We wish to thank John Green, Richard Ranson, and Dr. Phil Davey for technical support, Tania Cresswell-Maynard and Prof. Richard Geider for access to cultures, and Russell Smart for sample collection. This work was supported by a Natural Environment Research Council (NERC, UK) grant to D.J.Su., T.J.M., and D.J.Sm. (NE/F010184/1) and studentship to D.A.E. (NE/F009186/1).

DOI 10:4319/lom.2010.8.185 environmental stress (Sunda et al. 2002). In contrast, DMS production in terrestrial systems is relatively small (Simó 2001); whereas the VOC isoprene (2-methyl-1,3-butadiene), as one of the most reactive and abundant hydrocarbons emitted, has received considerably more attention (Sharkey et al. 2008; Sharkey and Yeh 2001). Isoprene rapidly oxidizes when released to the atmosphere which, in turn, can affect the residence time of gases that contribute to the greenhouse effect (Poisson et al. 2000), induce tropospheric ozone formation in the presence of nitric oxides (Monson and Holland 2001), and stimulate cloud condensation nuclei formation (Claeys et al. 2004; Sharkey and Yeh 2001).

Like DMS, isoprene is synthesized mainly by photoautotrophs as a direct secondary metabolite, potentially providing a number of ecophysiological benefits. For vascular plants isoprene primarily provides thermotolerance (Sharkey et al. 2008; Velikova et al. 2006). Specifically, isoprene molecules are partitioned into phospholipid bilayers, thus stabilizing membranes under stressful temperatures (Siwko et al. 2007). Isoprene also provides protection against oxidative stress (Loreto and Velikova 2001). Despite a wealth of research into isoprene production in the terrestrial environment (Sharkey et al. 2008; Sharkey and Yeh 2001), our knowledge of marine emissions of this important compound is limited. Only a small number of studies have been carried out, predominantly for phytoplankton 
(Acuña Alvarez et al. 2009; Baker et al. 2000; Mckay et al. 1996; Milne et al. 1995; Moore et al. 1994; Palmer and Shaw 2005; Shaw et al. 2003) but also temperate macroalgae (Broadgate et al. 2004). Such little emphasis on marine environments appears to be tied to suggestions that global atmospheric isoprene emission is substantially lower from marine systems (ca. $1 \mathrm{Tg} \mathrm{C} \mathrm{yr}^{-1}$ ) (Palmer and Shaw 2005) than from terrestrial systems (ca. $500 \mathrm{Tg} \mathrm{C} \mathrm{yr}^{-1}$ ) (Guenther et al. 1995). However, to date, these relatively low emission estimates from marine systems are based on few, and mostly laboratorybased, microalgal studies. Recent research has demonstrated that isoprene emissions from marine systems may be 2-5 times higher than previously estimated (Acuña Alvarez et al. 2009; Liakakou et al. 2007; Moore and Wang 2006) and, during microalgal blooms, could reach values $20 \%$ of those observed over the Amazon basin (Meskhidze and Nenes 2006). Furthermore, isoprene is an important source of carbon and energy for many marine heterotrophic bacteria (Acuña Alvarez et al. 2009). As yet, we know very little regarding the fluxes and global significance of isoprene production within marine systems, or how they will alter as our climate changes.

Measuring isoprene production-Isoprene production is conventionally quantified using gas chromatography (GC) in conjunction with a cryogenic pre-concentration method (Acuña Alvarez et al. 2009; Broadgate et al. 1997; Shaw et al. 2003). Typically, production is measured by incubating samples in gas-tight vessels for a number of hours, allowing isoprene to build up to a detectable level. Samples are then purged with an inert gas $\left(\mathrm{He}\right.$ or $\mathrm{N}_{2}$ ) for a time period suitable to remove the majority of isoprene present in the sample volume. The purged gas is either stored in a stainless steel canister, or in a coil kept at $-160^{\circ} \mathrm{C}$ using liquid nitrogen, which allows isoprene to accumulate in liquid state within the coil before being returned to its gaseous state with boiling water and diverted into the GC via a valve system. GC analysis is typically used in conjunction with a flame ionization detector (FID), a highly nonselective and sensitive detector that has been shown to detect hydrocarbons at a concentration below parts-per-billion-by-volume (ppbv), although accuracy and precision are substantially reduced at such low levels (Cao and Hewitt 1995).

Most studies generally recognize that this GC approach is labor intensive and costly; as a result, the sample turnover is slow. Extensive supplies of high quality compressed gases are required to perform GC analysis, and significant method training is essential. Storage during pre-concentration also has specific drawbacks. In particular, the reactivity of isoprene results in a loss over storage time (Greenberg and Zimmerman 1984), a factor which can greatly affect results when working at the pico- and nanomolar concentrations expected for marine samples (Broadgate et al. 2004; Shaw et al. 2003). A final limitation of GC analysis is the requirement of a sophisticated laboratory setting, leading to restrictions upon field work, especially in remote locations.
An alternative to GC analysis exploits chemiluminescence of the isoprene-ozone reaction to estimate isoprene concentration (Guenther and Hills 1998; Hills and Zimmerman 1990; Monson et al. 1991). Products of these reactions are formaldehyde (HCHO) and glyoxal (HCOCHO), both in an electronically excited state, which then emit light of wavelengths $(\lambda)$ of ca. 490 and $550 \mathrm{~nm}$, respectively, upon relaxation (Guenther and Hills 1998).

$$
\begin{gathered}
\text { Isoprene }\left(\mathrm{C}_{5} \mathrm{H}_{8}\right)+\text { Ozone }\left(\mathrm{O}_{3}\right) \rightarrow \mathrm{HCHO}^{*}+\text { products } \\
\text { Isoprene }\left(\mathrm{C}_{5} \mathrm{H}_{8}\right)+\text { Ozone }\left(\mathrm{O}_{3}\right) \rightarrow \mathrm{HCOCHO}^{*}+\text { products } \\
\mathrm{HCHO}^{*} \rightarrow \mathrm{HCHO}+h v(\lambda=490 \mathrm{~nm}) \\
\mathrm{HCOCHO}^{*} \rightarrow \mathrm{HCOCHO}+h v(\lambda=550 \mathrm{~nm})
\end{gathered}
$$

Photomultiplier detectors, operated in photon counting mode, can detect and count individual photons. This capability, combined with low background signals, allows extremely low detection limits, which for the isoprene- $\mathrm{O}_{3}$ system is $<0.02 \mathrm{nM}$ (0.5 ppbv), and response is linear over several orders of magnitude (Cao and Hewitt 1995; Toda and Dasgupta 2008). This approach has since been packaged into a commercially available Fast Isoprene Sensor (FIS) (developed by Hills Scientific http://hills-scientific.com), and has allowed research to examine, in more detail, the relationship between isoprene production and different environments and ecosystems.

In comparison to GC analysis, the FIS is fairly compact and therefore transportable for field application, and requires a lower degree of maintenance and gas supply. The FIS also provides continuous isoprene sampling at a resolution of $0.1 \mathrm{~s}$, enabling high-resolution real-time sampling that would be impossible to achieve using the more conventional GC-based protocols. A number of terrestrial studies of vascular plants have used the FIS successfully (Guenther and Hills 1998; Hills and Zimmerman 1990; Monson et al. 1991; Westberg et al. 2001; Zimmer et al. 2000). Importantly, this technology potentially opens up new possibilities in better understanding the extent and regulation of isoprene emissions by marine organisms. However, certain complications concerning the sampling of marine samples, particularly the necessary liberation of dissolved compounds into the gas phase, requires that the conventional terrestrial-based protocol needs to be modified, optimized, and standardized.

As part of an ongoing study into environmental regulation of isoprene production by marine organisms, we aimed to evaluate and optimize how the FIS could be applied to aquatic samples. Specifically, we wished to (1) examine the FIS' chemiluminescence detector for possible interference from other marine gases, (2) establish a detailed and standardized protocol for quantifying isoprene in marine environments using the FIS, (3) compare the performance (accuracy, resolution, and sensitivity) of this marine-based FIS protocol compared with the conventional GC method and, in doing so, (4) provide recommendations for the use of the FIS for future marine isoprene research. 


\section{Materials and procedure}

FIS optimization 1: setup-The Fast Isoprene Sensor (FIS) introduces ozone to the sample gas in a reflective reaction cell, while an opposing photomultiplier tube (PMT), sensitive to the required wavelengths, measures the light emitted by the reaction in single photon counting mode. Inputs to the FIS are compressed oxygen (to create the ozone required for reaction with isoprene) and an isoprene standard gas (for manual/automatic calibration of the sensor). For sample analysis, a diaphragm pump actively draws headspace gas into the reaction cell at a user-defined and electronically controlled flow rate, up to a maximum of $2000 \mathrm{~mL} \mathrm{~min}{ }^{-1}$. A commercially available Hamamatsu HC134 photon detector houses a Hamamatsu R6095P-03 PMT. Fig. 1 illustrates the complete setup of
FIS, ozonizer, gas supplies, and sampling vessel. More detailed specifications regarding the configuration of the FIS and earlier models have been previously described (Guenther and Hills 1998; Hills and Zimmerman 1990) while the latest instruments are presented at http://hills-scientific.com.

FIS setup consists of two parts: an ozone generator and the sensor unit itself, each with a weight of ca. $20 \mathrm{~kg}$. All fittings within these units are of stainless steel or Teflon, in order to resist reactive chemicals and reduce memory effects (Guenther and Hills 1998). External fittings, such as those connecting gas supplies and the sample vessel, were also of Teflon, and connected using stainless steel fittings (Swagelok). Despite the built-in catalytic converter scrubbing ozone from the carrier flow before exiting the FIS, an exhaust tube was used to safely direct waste gas externally. The user interface is in the form of
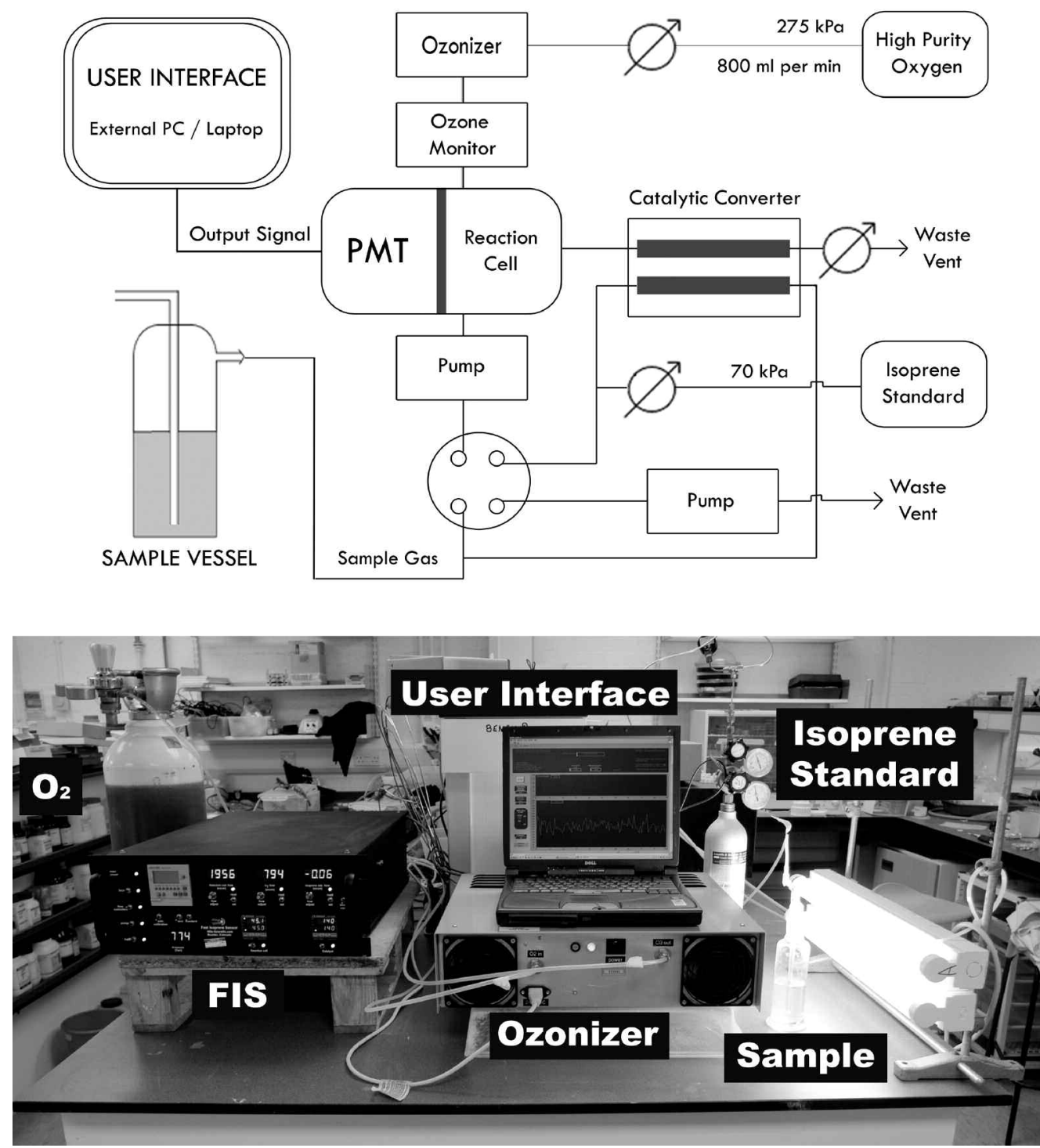

Fig. 1. Schematic diagram and photograph of the Fast Isoprene Sensor (FIS) and sample vessel setup as used in this study to measure isoprene emissions from marine samples (schematic adapted from Guenther and Hills 1998) (see main text for details). 
LabView software, which plots the photon counts over time and saves data to file. The averaging interval can be set manually within the software. For this study, a sampling interval of $0.1 \mathrm{~s}$ was used to provide high time resolution.

Sampling was performed using $250 \mathrm{~mL}$ quick-fit sealed borosilicate glass vessels, modified to include a glass aeration tube with circular opening reaching the base of the vessel. A Teflon tube was attached to an outlet port, permitting headspace to be drawn into the FIS from the sampling vessel. This process creates negative pressure within the vessel to induce bubbling from the aeration tube, which in turn liberates isoprene from the sample liquid. Preliminary work tested the use of sintered glass at various pore sizes to minimize bubble size and thus maximize the diffusion potential between the water and gas phase, but the added pressure prevented the pump from actively drawing headspace from sample vessels. Ultimately, these modifications proved unnecessary as we demonstrate a high correlation between GC and FIS techniques with subsequent configurations (see "Method Comparison"). Ambient air is used for bubbling, with background isoprene concentrations measured for each sample using a seawater blank; the isoprene concentration in this blank is subtracted from the sample concentration.

Initial tests determined that water volumes of ca. $150 \mathrm{~mL}$ (i.e., 60\% of the volume of the sealed glass vessel) were optimal so as to allow sufficient headspace within the vessels for gas sampling while simultaneously preventing bubblinginduced water droplets from entering the sampling outlet and thus reaching the reaction cell of the FIS. Sample vessels were temperature controlled in water baths and maintained under an actinic light source set to $150 \mu \mathrm{mol}$ photons $\mathrm{m}^{-2} \mathrm{~s}^{-1}$ to match conditions used for growth (Table 1).

Work on terrestrial systems has demonstrated that, regardless of the sample vessel design, some water vapor will inevitably enter the sample stream; however, this has been shown to have minimal effects on sensor performance unless working in high or variable humidity (Hills et al. 1998; Hills and Zimmerman 1990). The sensitivity of our system during marine sampling was similar to previously published results, suggesting that humidity levels are not high enough to create problems. Condensation along the sample path can be minimized by avoiding significant temperature variation between the sample vessel and FIS, while excessive build up within the sensor itself can be avoided by regular cleaning of the reaction cell, ideally between each period of experimentation (Hills et al. 1998). This can be performed easily with only a few hours hands-on time by washing the stainless steel reaction cell and the optical window in distilled water and mild detergent to remove any build up of dirt (either carried in the water vapor or the oxygen/ozone supply), and drying both in a $50^{\circ} \mathrm{C}$ drying oven. Compressed oxygen will also contain contaminants, particularly if $\mathrm{O}_{2}$ below ultra-high-purity (UHP) is used, with impurities such as $\mathrm{N}_{2}, \mathrm{H}_{2} \mathrm{O}$, and $\mathrm{CO}_{2}$. These impurities are not a major hindrance, but may increase background zero values due to chemiluminescence with ozone and lead to a build up of dirt in the system. It is not always possible to use UHP oxygen, especially when working in remote field locations, and so high-purity or lower has to be used. Therefore, signal drift before and after cleaning the optical components must be frequently evaluated under these conditions. The ozone generator cells may also require more frequent cleaning if belowUHP grade oxygen is used (ideally every 6 months) but again this is a quick and simple procedure and is carried out in the same way as for the reaction cell.

FIS optimization 2: protocols and settings-High Purity Compressed Oxygen (BOC Gases) was supplied to the FIS at 275 $\mathrm{kPa}$, where this flow was regulated at $800 \mathrm{~mL} \mathrm{~min}^{-1}$ by Tylan flow controllers housed within the FIS, and passed through the ozonizer unit before entering the reaction cell of the sensor. This pressure of $275 \mathrm{kPa}$ is required to drive the pneumatic valving within the FIS unit while the flow rate of $800 \mathrm{~mL}$ $\mathrm{min}^{-1}$ is required to prevent overheating of the ozonizer unit and ensure that there is sufficient ozone produced to drive the kinetics of the isoprene- $\mathrm{O}_{3}$ reaction (Guenther and Hills 1998). Once $\mathrm{O}_{2}$ supply and ozonizer are switched on, a minimum 1-h warm-up period allows the FIS to warm up and the signal to fully stabilize (manufacturer's recommendation).

The FIS is capable of microprocessor-based auto-calibration at a frequency defined by the user. For this study, however, we chose to manually calibrate the sensor at times that suited our sampling schedule, using a $60 \mathrm{~L}$ disposable cylinder of $6 \mathrm{ppmv}$ $(4.33 \mu \mathrm{M})$ isoprene in helium calibration gas (Scientific and Technical Gas) supplied at a continuous pressure of $70 \mathrm{kPa}$, and varied flow rate to achieve multiple concentrations in the sample flow. Before each calibration, the standard gas supply was bled for ca. $10 \mathrm{~s}$ to remove the isoprene, which had been standing in the connections and tubing and thus could have degraded over time. The FIS response to the isoprene standard is linear $\left(r^{2}=0.997\right.$, Fig. 2); therefore regular calibration requires only a zero count to determine background noise fol-

Table 1. Summary information of species used to assess comparability of GC and FIS analysis of isoprene production. All other growth and experimentation conditions were kept constant (light intensity $=150 \mu \mathrm{mol}$ photons $\mathrm{m}^{-2} \mathrm{~s}^{-1}$, PSU $=35$ and maintained in $\mathrm{f} / 2 \mathrm{media}$ ).

\begin{tabular}{lccc}
\hline Species & Strain & Class & Growth Temp $\left({ }^{\circ} \mathrm{C}\right)$ \\
\hline Thalassiosira weissflogii (Grun.) & CCMP1336 & Coscinodiscophyceae & 15 \\
Emiliania huxleyi (Lohm.) & CCMP1516 & Prymnesiophyceae & 19 \\
Fucus vesiculosus (L.) & $\mathrm{n} / \mathrm{a}$ & Phaeophyceae & 15 \\
\hline
\end{tabular}




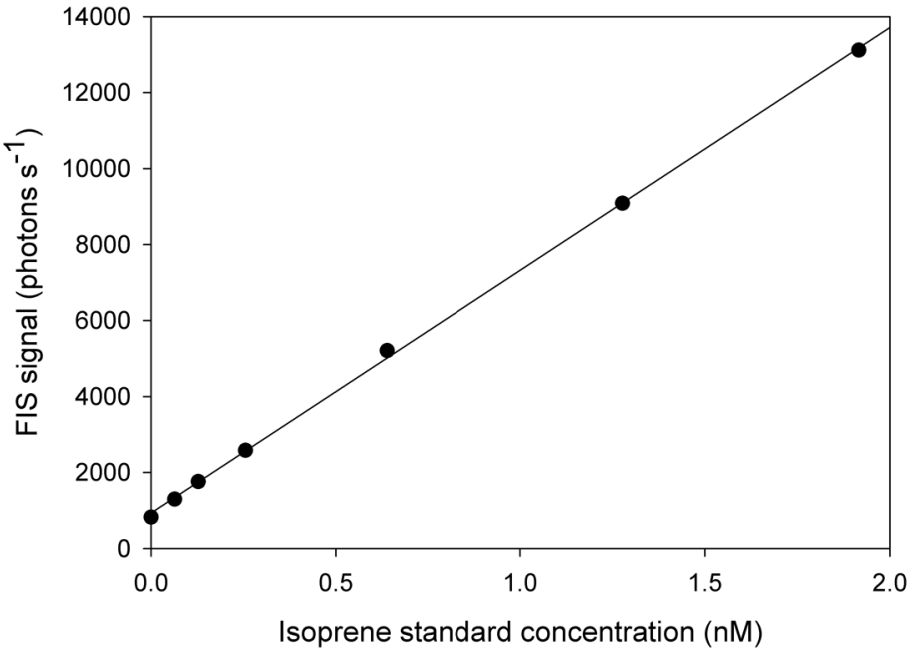

Fig. 2. Calibration plot for the FIS using $6 \mathrm{ppmv}$ isoprene standard gas in helium at a range of concentrations $\left(r^{2}=0.999\right.$, slope $=6387.8$, y-intercept $=936.6$ ), achieved through modification of the standard gas flow rate to the reaction cell. The $y$-intercept point provides a background zero value, while the slope of the line provides FIS sensitivity (photons $\mathrm{s}^{-1} \mathrm{nM}$ isoprene ${ }^{-1}$ ).

lowed by a single reading of standard at a known flow rate (for

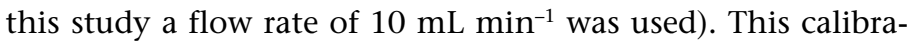
tion response yields both the zero count of background noise (the y-intercept value) and the calibration conversion factor (the slope, photon counts $\mathrm{nM}^{-1}$ isoprene).

The sample vessel is attached to the sample inlet port of the FIS, and the FIS run in sample mode at a reaction cell flow rate of $1900 \mathrm{~mL} \mathrm{~min}{ }^{-1}$. Using the maximum sample flow rate of $2000 \mathrm{~mL} \mathrm{~min}^{-1}$ should be avoided where possible since the flow controllers are completely open and thus not in full control of the flow rate; in contrast, lower flow rates struggle to maintain sufficient bubbling in the sample vessel.

Trial runs demonstrated an initial isoprene peak due to preexisting isoprene in the water body and headspace being sampled (see Fig. 3). Unless the rate of this build up is known, data must be discarded. Instead the sample is run until a continuous steady state is achieved. Following subtraction of a seawater blank, the steady state yield over time represents isoprene production per unit time. This is supported by the analysis of solutions of isoprene in sterile ASW (artificial seawater) which, when run through the FIS, followed a similar decrease as seen in sample analysis (see Fig. 3), as the preexisting isoprene is purged, but with no steady state yield. This demonstrates that the steady state yield seen during sample analysis represents isoprene produced by the sample once all preexisting isoprene within the vessel has been removed.

\section{Assessment}

Signal interference by additional trace gases-Isoprene is not the only compound to chemiluminesce upon reaction with ozone, with various trace gases following similar reactions (Guenther and Hills 1998; Toda and Dasgupta 2008); as such,

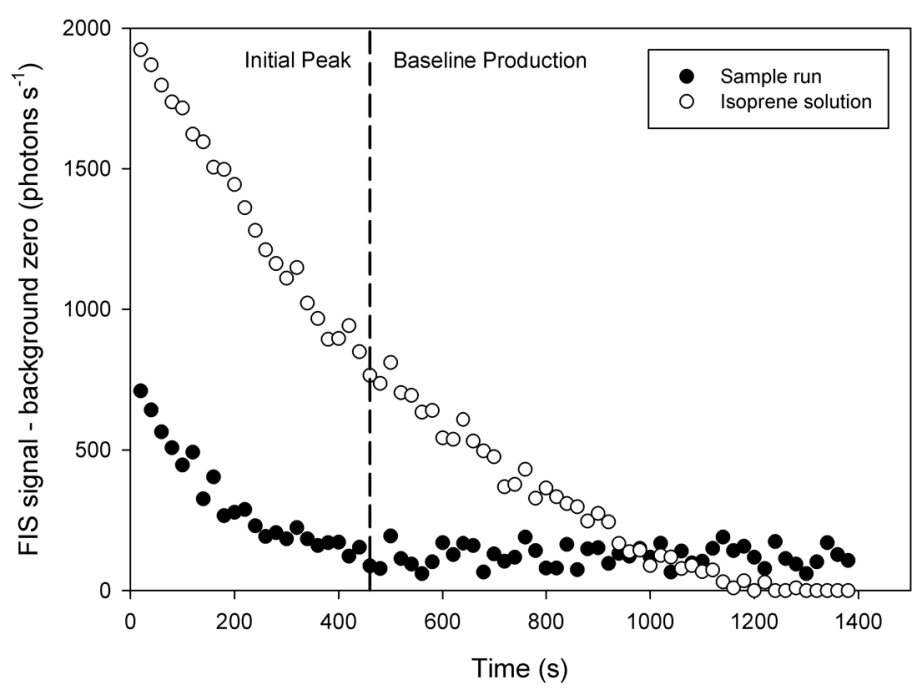

Fig. 3. Sample plot of the FIS signal (photons $\mathrm{s}^{-1}$ ) recorded through LabView software while sampling a Thalassiosira weissflogii CCMP1336 culture and a solution of isoprene in sterile ASW. The sample plot demonstrates an initial peak followed by a steady state baseline production of isoprene, while the isoprene solution plot supports baseline production. Dashed vertical line illustrates the start of baseline production in the sample run. Data shown at a resolution of $20 \mathrm{~s}$.

there is a potential for interference when using chemiluminescence analysis solely to detect isoprene. Certain precautions can be made, as different compounds produce a range of photon wavelengths, and detectors are specifically adapted for measurement of different compounds (Toda and Dasgupta 2008). During the initial development of the FIS, the sensor's response to a total of 15 compounds was tested, providing response factors relative to isoprene for each (Hills and Zimmerman 1990). Of the 15 compounds tested, only propene gave a response factor of 1.0, meaning that the FIS will detect both isoprene and propene equally since their signals are indistinguishable from one another. Another alkene (ethene) gave a response factor of 0.15 . Previous assessments of the FIS have concluded that these gases will not contaminate the isoprene signal for terrestrial systems since propene and ethene do not exist in significant levels in these environments (Guenther and Hills 1998; Hills and Zimmerman 1990); however, this problem must be readdressed when attempting to work with marine samples.

Studies into hydrocarbon emissions from marine sources have demonstrated that both propene and ethene are present in natural seawater at concentrations equal to or higher than isoprene (Riemer et al. 2000), but that they are produced by abiotic photochemistry acting on dissolved organic carbon (Ratte et al. 1998; Riemer et al. 2000). Although some macroalgal production has been shown (Broadgate et al. 2004; Plettner et al. 2005), phytoplankton studies have demonstrated a lack of biogenic production (Mckay et al. 1996; Shaw et al. 2003). However, more detailed experiments concluded that this photochemical production of alkenes is driven by light in the range $290-420 \mathrm{~nm}$ 
(Ratte et al. 1998). As UV wavelengths are excluded from experiments when using borosilicate glass sample vessels, the photochemical production of alkenes can be easily eliminated.

Of particular concern regarding marine sampling is potential interference caused by dimethyl sulphide [DMS, $\left(\mathrm{CH}_{3}\right)_{2} \mathrm{~S}$ ]. Hills and Zimmerman (1990) report an interference factor of 0.54 for DMS and, due to the lower wavelength emission of the DMS- $\mathrm{O}_{3}$ reaction, demonstrated that the introduction of an optical filter (Corning GG-475) effectively reduced this to 0.12. Although terrestrial studies have been able to ignore this compound due to the extremely low concentration in these environments (Hills et al. 1998), DMS concentrations in marine systems are typically several orders of magnitude greater than those of isoprene. British coastal seawater, for example, has been shown to contain summer concentrations of $20 \mathrm{pM}$ isoprene (Broadgate et al. 2004) and 6.9 nM DMS (Turner et al. 1988). We therefore tested the use of alternative optical filters to reduce the DMS signal. The filter that gave the best results was a Lee-100 longpass filter (Lee Filters), which blocks light of wavelengths $<450 \mathrm{~nm}$, and could be conveniently held against the optical window by the o-ring fittings. With this filter in place, the DMS signal was reduced to below the detection limit at concentrations lower than $0.42 \mathrm{mM}$, and by $>99 \%$ between 0.42 and $4.12 \mathrm{mM}$ (see Fig. 4a). One of the highest recorded DMS concentrations (ca. $19 \mu \mathrm{M}$ ) has been recorded in the mucus of the scleractinian coral Acropora formosa (Broadbent and Jones 2004); as such, our data would imply that the Lee-100 longpass filter should remove DMS interference from even the most productive environments. The drawback to using a filter is that the isoprene signal (i.e., sensitivity) will also be affected substantially (Fig. 4b). Specifically, the isoprene signal was decreased by $60 \%$ on average when running an isoprene standard calibration with the Lee-100 longpass filter in place. That said, the FIS detection response to the isoprene standard remained linear $\left(r^{2}=0.991\right.$, compared with an $r^{2}$ of 0.997 without the filter) and was able to detect the calibration gas at concentrations as low as $0.02 \mathrm{nM}(0.5 \mathrm{ppbv})$ with the filter in place. This value is below concentrations measured in marine samples for many studies, from a range of organisms and environments (Acuña Alvarez et al. 2009; Broadgate et al. 2004; Moore et al. 1994; Riemer et al. 2000).

The remaining 12 compounds all showed response factors of 0.19 or below and, combined with their low natural concentrations, can be dismissed as insignificant interference (Guenther and Hills 1998; Hills and Zimmerman 1990).

Despite the lower sensitivity, the application of an optical filter affords the advantages of using the FIS over the GC, i.e., the convenience for large scale (and possibly remote) sampling of isoprene. Importantly, the FIS now provides a highly selective isoprene signal.

Method comparison-Having optimized the instrument for marine samples (above), we wished to compare the performance of the FIS against a conventional GC-based method for measuring isoprene production by marine organisms; for this, identical samples were run through both as follows. Samples
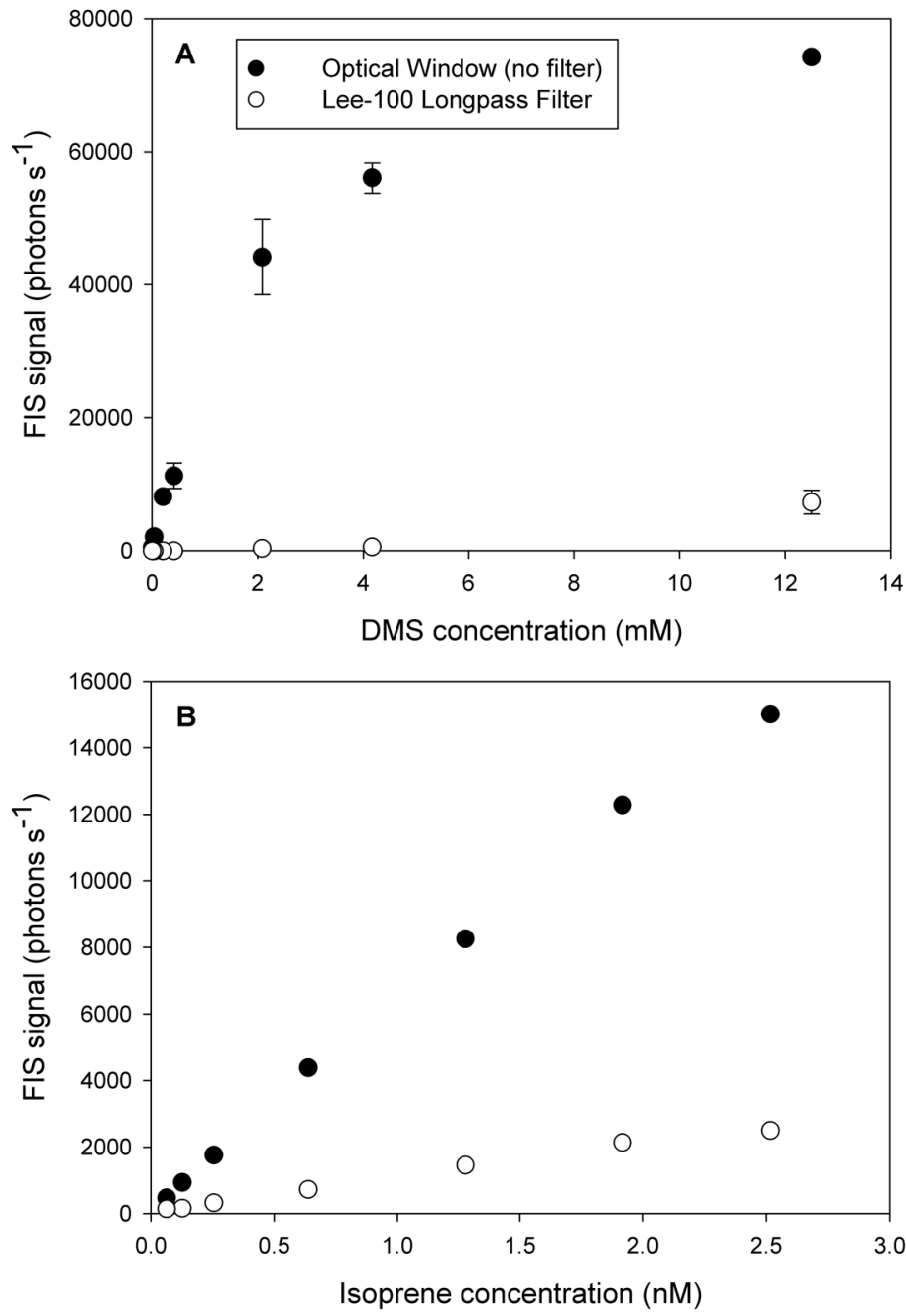

Fig. 4. Response of the Fast Isoprene Sensor (FIS) signal (photons $\mathrm{s}^{-1}$ ) to gaseous standards of (a) dimethyl sulphide and (b) isoprene, both in the presence and absence of a Lee-100 longpass filter. Data are the mean ( \pm standard error) for triplicate runs with the background zero subtracted. Note that isoprene calibration data from Fig. 2 is repeated here for comparative purposes.

of two laboratory cultured microalgae (Emiliania huxleyi CCMP1516 and Thalassiosira weissflogii CCMP1336) and one naturally sourced macroalgae (Fucus vesiculosus, collected on 15 June 2009 from the Colne Estuary, Essex, UK) (Table 1) were analyzed with the FIS until a baseline production level was reached. Each sample $(150 \mathrm{~mL})$ was then incubated in 250 $\mathrm{mL}$ sealed purge vessels at $15^{\circ} \mathrm{C}\left(19^{\circ} \mathrm{C}\right.$ for $E$. huxleyi $)$ and at a light intensity of $150 \mu \mathrm{mol}$ photons $\mathrm{m}^{-2} \mathrm{~s}^{-1}$ for $3 \mathrm{~h}$ ). They were then purged for 40 min using compressed high purity helium (BOC Gases) at $80 \mathrm{~mL} \mathrm{~min}^{-1}$, and liberated gases were trapped in liquid nitrogen, as described above, before analysis using GC-FID. Prior to sampling, cell counts using a Neubauer haemacytometer (Fisher Scientific) were carried out for microalgae, and wet weight taken for macroalgal samples.

A dilution experiment was performed to examine the level of similarity between GC-FID and FIS techniques at a range of 
biomass levels, but also to identify the minimum detectable isoprene production rates. Microalgae were diluted using ASW enriched with f/2 (Guillard 1975), while different quantities of macroalgal material were used each time. This experiment was repeated in triplicate for all three study organisms. Both GCFID and FIS were calibrated daily throughout this experiment. All FIS measurements were performed using the Lee-100 longpass filter in place.

All three species demonstrated similar rates of isoprene production using the two techniques (Fig. 5). Bartlett's type II regressions yielded values $\left(r^{2}\right.$, slope) that ranged from 0.738 , 0.941 for E. huxleyi, to $0.886,1.027$ for T. weissflogii and 0.981, 0.699 for $F$. vesiculosus. When combined into a single data set, the regression analysis gave an $r^{2}$ of 0.910 and slope of 1.002 (see Table 2). It is important to note here that concentrations that were below the detection limit for FIS analysis were discounted from the regression analysis. Detection limits of isoprene production for the FIS were $1.4 \times 10^{-16} \mathrm{~mol} \mathrm{cell}^{-1} \mathrm{~h}^{-1}$ for $E$. hux (with $150 \mathrm{~mL}$ culture at 30,000 cells $\mathrm{mL}^{-1}$ ), $7.9 \times 10^{-17} \mathrm{~mol} \mathrm{cell}^{-1} \mathrm{~h}^{-1}$ for T. weissflogii (with $150 \mathrm{~mL}$ culture at 50,000 cells $\mathrm{mL}^{-1}$ ), and 0.61 $\mathrm{nmol} \mathrm{h}^{-1}$ for $F$. vesiculosus (0.816 $\mathrm{g}$ wet weight). For microalgal samples, these equate to $0.532 \mathrm{mmol}$ isoprene ( $\mathrm{g}$ Chlorophyll $a)^{-1} \mathrm{~h}^{-1}$ for $E$. hux, and $0.078 \mathrm{mmol}$ isoprene $(\mathrm{g} \mathrm{Chl} a)^{-1} \mathrm{~h}^{-1}$ for $T$. weissflogii. Although these production values are higher than some previously published, the use of different culture strains and growth conditions could account for this.

Importantly, these results demonstrate the potential use of the FIS to analyze microalgae in high abundance, such as algal blooms and laboratory cultures, along with multicellular photoautotrophs. However, the minimum detection limits imply that examining many natural non-bloom phytoplankton communities, such as low productivity open ocean samples, will not be possible without pre-concentrating isoprene. As such, our data illustrate the continuing benefit of pre-concentrated GCFID sampling for low biomass levels, particularly natural water samples where microalgal populations may be small; however, for samples with high isoprene production, FIS analysis provides data highly similar to that obtained from GC-FID. The high level of similarity between the two techniques also demonstrates that signals from interfering compounds have been successfully reduced by the use of the Lee-100 longpass filter.

A final experiment was performed to assess the reproducibility of the FIS technique developed during this study. To achieve this, triplicate cultures of $T$. weissflogii, kept at the same cell densities, were analyzed using the FIS. This was repeated for five different biomass levels, and the standard error of the triplicate samples used to demonstrate the level of reproducibility of this technique and to identify whether any margin of error increases as the detection limit is reached. This experiment demonstrated small standard errors throughout, i.e., no significant increase in error as biomass increased (Fig. 6). Therefore, these results support the previous aspects of this study in demonstrating the suitability of FIS analysis for sampling of marine isoprene.

\section{Discussion}

This study has demonstrated that the FIS is a reliable new method for marine sampling of isoprene production. It provides data that are strongly correlated with GC analysis when biomass levels are suitable and precautions have been made to avoid interference of the signal. Strong reproducibility also

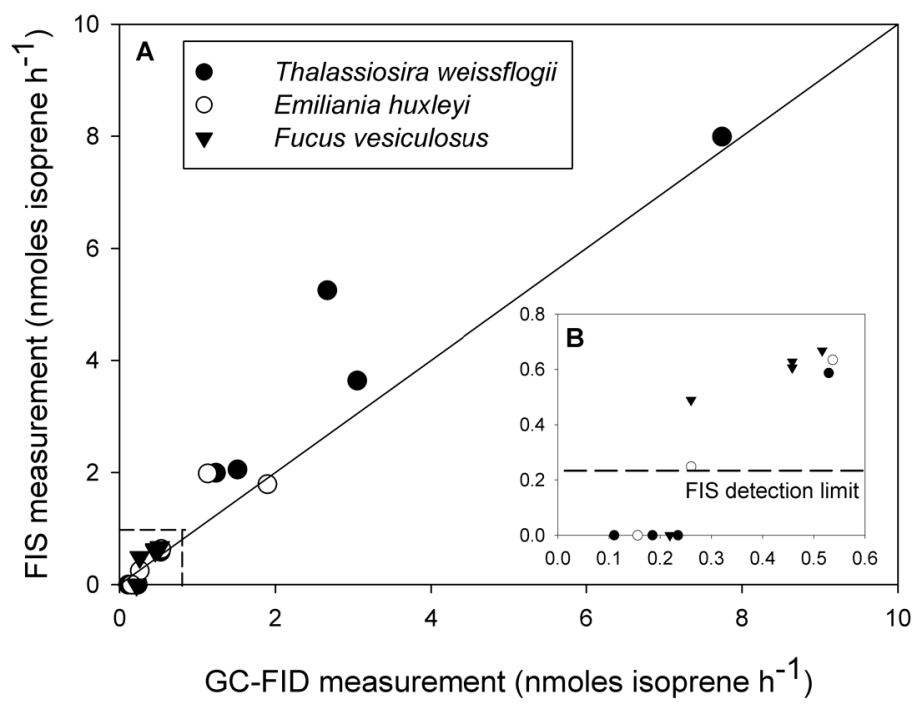

Fig. 5. Comparison of the rate of isoprene production $\left(\mathrm{nmol} \mathrm{h} \mathrm{h}^{-1}\right)$ measured sequentially by FIS and GC-FID analysis for species of micro- and macro-algae. For each species, a range of sample sizes were examined to identify the lowest detection limits. Individual sample data are plotted against a 1:1 line plot (A), with low production values shown in inset (B) to highlight the FIS detection limit. Note that a zero detection limit was observed for the FIS only.

Table 2. Bartlett's type II regression values for isoprene production measured by GC ( $x$ axis) and FIS ( $y$ axis) (see Fig. 5). Regressions were performed for each species but also for all data combined; all slopes and intercept fits were significant for $P<0.05$; data shown is the slope and intercept fit and the coefficient of variation (lower, upper). Data obtained below the detection limit of the FIS are omitted from regression analysis.

\begin{tabular}{lccr}
\hline Species & $r^{2}$ & Slope & Intercept \\
\hline Thalassiosira weissflogii & 0.886 & $1.027(1.002,1.052)$ & $1.037(1.459,3.474)$ \\
Emiliania huxleyi & 0.738 & $0.941(0.928,0.954)$ & $0.069(-0.266,0.404)$ \\
Fucus vesiculosus & 0.981 & $0.699(0.697,0.701)$ & $7.377(7.359,7.395)$ \\
Combined & 0.910 & $1.003(0.976,1.028)$ & $5.480(3.006,8.037)$ \\
\hline
\end{tabular}




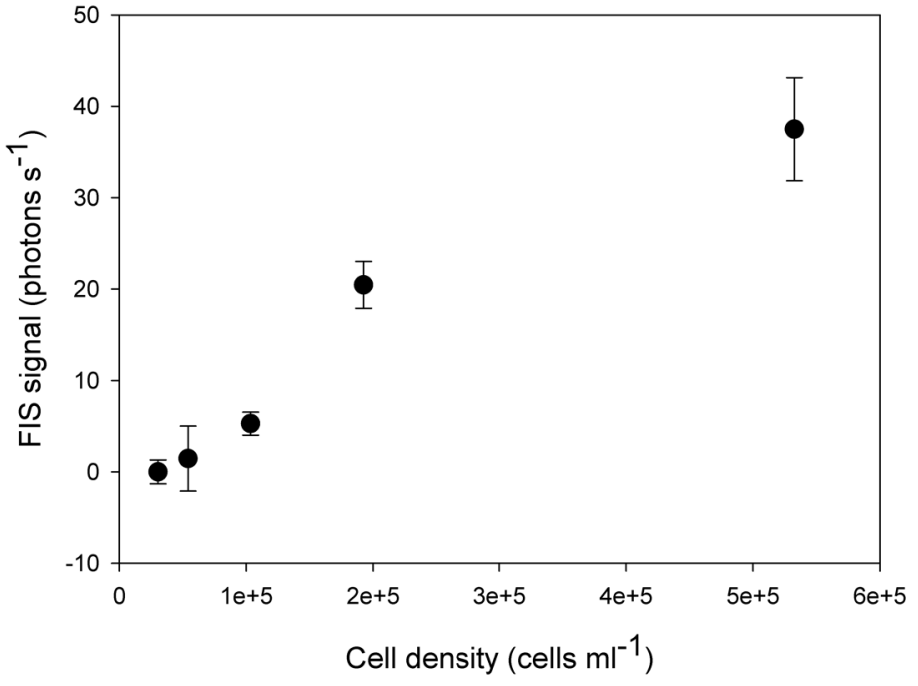

Fig. 6. Reproducibility of FIS analysis using $150 \mathrm{~mL}$ Thalassiosira weissflogii CCMP1336 cultures diluted to a range of cellular concentrations. Data shown is the mean ( \pm standard error) FIS signal (photons $\mathrm{s}^{-1}$ ) with the seawater blank subtracted for triplicate runs.

allows results to be used with a high degree of confidence. The Lee-100 longpass filter used in this study to minimize interference from DMS, identified as the greatest concern due to its high natural concentrations in comparison to isoprene (Broadgate et al. 2004; Turner et al. 1988), decreased DMSderived signal to below the detection limit at concentrations well above naturally relevant levels, even for the most concentrated samples, as seen in coral mucus (Broadbent and Jones 2004). The use of both micro- and macroalgal samples in this study demonstrate that a range of taxonomic groups can be analyzed using the described technique with similar levels of success in terms of comparability with the established GC technique.

Although there are potential concerns regarding the ability of the bubbling rate described in this study to completely remove produced isoprene, and thus that the FIS may underestimate isoprene production, the strong correlation with GC measurements suggest that any artifact related to this issue is the same for existing techniques. Any effects of incomplete removal of produced isoprene will also be the same for all samples, making isoprene production values measured using this method comparable with one another. The minimum biomass levels required for FIS analysis is another potential limitation for working with natural concentrations of material, for example phytoplankton from the open ocean. However, preconcentration of biomass in such samples, such as through tangential flow combined with diffusion, would still potentially afford the FIS advantages over use of the GC in terms of resolution. In particular, responses in isoprene production with changing environmental conditions can be potentially assessed in real time, with any up-regulation in production identified within seconds; however this is an area of ongoing investigation. The fast turnover rate of samples for isoprene production rate measurements under a controlled set of environmental conditions (ca. 10 min sample ${ }^{-1}$ for FIS, compared 2-4 hours for GC-FID) also means that data points from replicate samples can be obtained in a much higher frequency than GC analysis with pre-concentrating incubations will allow. Similarly, the high resolution (0.1 s) would enable in-line monitoring of microalgal cultures or dense natural communities (e.g., microphytobenthic communities, blooms, and microcosm experiments) but also any multicellular photoautotroph that exists in relatively high biomass (e.g., macroalgae, corals, seagrasses). Recent developments at Hills-Scientific in short-coupled optics and enhanced reflective optics have boosted FIS sensitivity by a factor of four, compared with the instrument used here, increasing the likelihood of direct isoprene measurements from low emitting or low biomass marine samples.

Another advantage of FIS analysis is in field work, where its relatively simple setup, low maintenance requirements, and basic consumable needs make it a suitable tool for carrying out research away from a standard laboratory setting. Therefore, the findings of our study potentially open up a range of new field applications for marine trace gas sampling. This includes allowing habitats previously difficult or even impossible to analyze in situ to be incorporated into research efforts that, in particular, aim to understand the environmental regulation of isoprene. Despite these potential opportunities, we have conducted preliminary experiments that potentially highlight a number of limitations to field work with the FIS that should be mentioned. Primarily, our initial work in remote field locations (unpubl. data) demonstrated that obtaining the required consumables (compressed oxygen and isoprene standard gas) is difficult and, in many countries, UHP or even high purity oxygen is simply unavailable, with medical grade the only option. As always, any changes from our initial evaluation and subsequent recommendations (below) to suit specific needs or working conditions will inevitably require additional tests to be performed.

In summary, we have demonstrated that the FIS is potentially highly applicable to marine studies of isoprene production through relatively minor modifications of preexisting protocols. We wish to note that this study was carried out to evaluate FIS-based analysis of marine algal samples, and to provide an insight into its potential role where existing techniques are currently largely unsuitable, certainly for routine investigations. It is in no way a criticism of the use of GCbased analysis used previously to quantify marine isoprene production; as such, existing GC-based isoprene data should still be considered robust. The use of GC in combination with preconcentration techniques will undoubtedly remain the 'norm' within this field, but the FIS can now be considered a reliable alternative and, more importantly, be able to broaden the scope of research in the field of marine isoprene. The high resolution, accuracy, and portability of the FIS may ultimately 
be of huge benefit to the substantial community already analyzing the biogeochemical dynamics of traces gases in the marine environment that must currently rely on GC-based approaches.

\section{Recommendations}

During the various stages of this study, we have evaluated a number of protocols to ensure that the analysis of marine samples by the FIS using the current configuration is optimally maintained and that data quality is maximized. Although many of these points have already been raised previously, they are summarized as follows:

(1) Cleaning of the reaction chamber and ozonizer cells should be carried out more regularly than recommended by the manufacturer due to the problems associated with marine samples, particularly water vapor and liberated aerosols. This is especially important if below-UHP oxygen is being used as impurities may lead to increased fouling, as may compounds liberated from the sample itself. The authors recommend that the reaction chamber be cleaned after each experimental period, or after a month of continuous/regular use, whichever comes first, and the ozonizer cells cleaned every 6 months.

(2) To avoid water droplets entering the FIS, a significant headspace to sample volume ratio should be maintained. The authors suggest $40 \%$ headspace, and an outlet valve from the sample vessel at least $10 \mathrm{~cm}$ from the sample surface. Condensation of water vapor in the Teflon tubing connecting the sample vessel to the FIS should also be avoided, and this can be achieved by ensuring that there is little to no temperature variation between the sample vessel and connecting tubing. With these simple precautions taken, the analysis of marine samples can be carried out as described without the negative effects of extensive water vapor ingestion.

(3) Due to the detection limit of FIS analysis, which is degraded by the use of a Lee-100 longpass filter to remove signal interference, low biomass levels or open ocean (nonbloom) water samples may not produce isoprene at a rate that is detectable by the FIS. Any modification or servicing of the FIS will require that (in addition to absolute calibration) the resolution and detection limit be re-evaluated for the study in question. Readers should note here that a new model FIS increases sensitivity by a factor of four and could negate the loss of signal by the use of an optical filter.

(4) Field work using the FIS should be carefully planned to ensure all components of the total setup are available on site. This recommendation should not dissuade researchers from using the benefits of FIS analysis at marine field sites, but simply ensure that careful planning is undertaken. Any modifications to the standard protocols, such as purity of oxygen, should be strictly re-evaluated in terms of signal reproducibility and deterioration over time.

(5) Although this study demonstrates the benefits of using FIS analysis for marine isoprene research, it also raises the possibility that, with the correct optical filter, other trace gases could also be measured accurately, in particular DMS; therefore, further research is recommended to explore this possibility fully.

\section{References}

Acuña Alvarez, L., D. Exton, D. J. Suggett, K. N. Timmis, and T. J. Mcgenity. 2009. Characterization of marine isoprenedegrading communities. Environ. Microbiol. 11:3280-3291 [doi:10.1111/j.1462-2920.2009.02069.x].

Baker, A. R., and others. 2000. Distribution and sea-air fluxes of biogenic trace gases in the eastern Atlantic Ocean. Global Biogeochem. Cycl. 14:871-886 [doi:10.1029/1999GB001219].

Bates, T. S., R. J. Charlson, and R. H. Gammon. 1987. Evidence for the climatic role of marine biogenic sulfur. Nature 329:319-321 [doi:10.1038/329319a0].

Broadbent, A. D., and G. B. Jones. 2004. DMS and DMSP in mucus ropes, coral mucus, surface films and sediment pore water from coral reefs in the Great Barrier Reef. Mar. Freshw. Res. 55:849-855 [doi:10.1071/MF04114].

Broadgate, W. J., P. S. Liss, and S. A. Penkett. 1997. Seasonal emissions of isoprene and other reactive hydrocarbon gases from the ocean. Geophys. Res. Lett. 24:2675-2678.

, G. Malin, F. C. Küpper, A. Thompson, and P. S. Liss. 2004. Isoprene and other non-methane hydrocarbons from seaweeds: a source of reactive hydrocarbons to the atmosphere. Mar. Chem. 88:61-73 [doi:10.1016/j.marchem.2004.03.002].

Cao, X., and C. N. Hewitt. 1995. detection methods for the analysis of biogenic non-methane hydrocarbons in Air. J. Chromatogr. 710:39-50.

Charlson, R. J., J. E. Lovelock, M. O. Andreae, and S. G. Warren. 1987. Oceanic phytoplankton, atmospheric sulfur, cloud albedo and climate. Nature 326:655-661.

Claeys, M., and others. 2004. Formation of secondary organic aerosols through photooxidation of isoprene. Science 303:1173-1176 [doi:10.1126/science.1092805].

Fink, P. 2007. Ecological functions of volatile organic compounds in aquatic systems. Mar. Freshw. Behav. Physiol. 40:155-168 [doi:10.1080/10236240701602218].

Greenberg, J. P., and P. R. Zimmerman. 1984. Nonmethane hydrocarbons in remote tropical, continental, and marine atmospheres. J. Geophys. Res. Atmos. 89:4767-4778.

Guenther, A., and others. 1995. A global-model of natural volatile organic-compound emissions. J. Geophys. Res. Atmos. 100:8873-8892.

Guenther, A. B., and A. J. Hills. 1998. Eddy covariance measurement of isoprene fluxes. J. Geophys. Res. Atmos. 103:13145-13152.

Guillard, R. R. L. 1975. Culture of phytoplankton for feeding marine invertebrates. In W. L. Smith and M. H. Chanley [eds.], Culture of marine invertebrate animals. Plenum.

Hills, A. J., and P. R. Zimmerman. 1990. Isoprene measurement by ozone-induced chemiluminescence. Anal. Chem. 62:1055-1060.

—, D. H. Lenschow, and J. W. Birks. 1998. Dimethyl sul- 
fide measurement by fluorine-induced chemiluminescence. Anal. Chem. 70:1735-1742.

Kettle, A. J., and M. O. Andreae. 2000. Flux of dimethylsulfide from the oceans: A comparison of updated data seas and flux models. J. Geophys. Res. Atmos. 105:26793-26808.

Liakakou, E., M. Vrekoussis, B. Bonsang, C. Donousis, M. Kanakidou, and N. Mihalopoulos. 2007. Isoprene above the Eastern Mediterranean: Seasonal variation and contribution to the oxidation capacity of the atmosphere. Atmos. Environ. 41:1002-1010 [doi:10.1016/j.atmosenv.2006.09.034].

Loreto, F., and V. Velikova. 2001. Isoprene produced by leaves protects the photosynthetic apparatus against ozone damage, quenches ozone products, and reduces lipid peroxidation of cellular membranes. Plant Physiol. 127:1781-1787 [doi:10.1104/pp.010497].

McKay, W. A., M. F. Turner, B. M. R. Jones, and C. M. Halliwell. 1996. Emissions of hydrocarbons from marine phytoplankton - Some results from controlled laboratory experiments. Atmos. Environ. 30:2583-2593.

Meskhidze, N., and A. Nenes. 2006. Phytoplankton and cloudiness in the Southern Ocean. Science 314:1419-1423 [doi:10.1126/science.1131779].

Milne, P. J., D. D. Riemer, R. G. Zika, and L. E. Brand. 1995. Measurement of vertical-distribution of isoprene in surface seawater, its chemical fate, and its emission from several phytoplankton monocultures. Mar. Chem. 48:237-244.

Monson, R. K., A. J. Hills, P. R. Zimmerman, and R. R. Fall. 1991. Studies of the relationship between isoprene emission rate and co2 or photon-flux density using a real-time isoprene analyzer. Plant Cell Environ. 14:517-523.

_ their control over tropospheric chemistry. Ann. Rev. Ecol. System. 32:547 [doi:10.1146/annurev.ecolsys.32.081501.114136].

Moore, R. M., D. E. Oram, and S. A. Penkett. 1994. Production of isoprene by marine-phytoplankton cultures. Geophys. Res. Lett. 21:2507-2510.

__- and L. Wang. 2006. The influence of iron fertilization on the fluxes of methyl halides and isoprene from ocean to atmosphere in the SERIES experiment. DeepSea Res. II Topical Stud. Oceanogr. 53:2398-2409 [doi:10.1016/j.dsr2.2006.05.025].

Palmer, P. I., and S. L. Shaw. 2005. Quantifying global marine isoprene fluxes using MODIS chlorophyll observations. Geophys. Res. Lett. 32:L09805 [doi.10.1029/2005GL0 22592].

Plettner, I., M. Steinke, and G. Malin. 2005. Ethene (ethylene) production in the marine macroalgae Ulva (Enteromorpha) intestinalis L. (Chlorophyta, Ulvophyceae): Effect of light-stress and co-production with dimethyl sulphide (DMS). Plant Cell Environ. 28:1136-1145 [doi:10.1111/j.1365-3040.2005.01351.x].

Poisson, N., M. Kanakidou, and P. J. Crutzen. 2000. Impact of non-methane hydrocarbons on tropospheric chemistry and the oxidizing power of the global troposphere: 3-dimensional modelling results. J. Atmos. Chem. 36:157-230.

Ratte, M., O. Bujok, A. Spitzy, and J. Rudolph. 1998. Photochemical alkene formation in seawater from dissolved organic carbon: Results from laboratory experiments. J. Geophys. Res. Atmos. 103:5707-5717.

Riemer, D. D., P. J. Milne, R. G. Zika, and W. H. Pos. 2000. Photoproduction of nonmethane hydrocarbons (NMHCs) in seawater. Mar. Chem. 71:177-198.

Sharkey, T. D., and S. S. Yeh. 2001. Isoprene emission from plants. Annul Rev. Plant Physiol. Plant Mol. Biol. 52:407436 [doi:10.1146/annurev.arplant.52.1.407].

—, A. E. Wiberley, and A. R. Donohue. 2008. Isoprene emission from plants: Why and how. Ann. Bot. 101:5-18 [doi:10.1093/aob/mcm240].

Shaw, S. L., S. W. Chisholm, and R. G. Prinn. 2003. Isoprene production by Prochlorococcus, a marine cyanobacterium, and other phytoplankton. Mar. Chem. 80:227-245 [doi:10.1016/S0304-4203(02)00101-9].

Simó, R. 2001. Production of atmospheric sulfur by oceanic plankton: biogeochemical, ecological and evolutionary links. Trends Ecol. Evol. 16:287-294 [doi:10.1016/S0169-5347(01)02152-8].

Siwko, M. E., S. J. Marrink, A. H. De Vries, A. Kozubek, A. Uiterkamp, and A. E. Mark. 2007. Does isoprene protect plant membranes from thermal shock? A molecular dynamics study. Biochim. Biophys. Acta Biomembr. 1768:198-206 [doi:10.1016/j.bbamem.2006.09.023].

Stefels, J., M. Steinke, S. Turner, G. Malin, and S. Belviso. 2007. Environmental constraints on the production and removal of the climatically active gas dimethylsulphide (DMS) and implications for ecosystem modelling. Biogeochemistry 83(1-3):245-275 [doi:10.1007/s10533-007-9091-5].

Steinke, M., G. Malin, and P. S. Liss. 2002. Trophic interactions in the sea: An ecological role for climate relevant volatiles? J. Phycol. 38:630-638 [doi:10.1046/j.1529-8817.2002.02057.x].

, J. Stefels, and E. Stamhuis. 2006. Dimethyl sulfide triggers search behavior in copepods. Limnol. Oceanogr. 51:1925-1930.

Sunda, W., D. J. Kieber, R. P. Kiene, and S. Huntsman. 2002. An antioxidant function for DMSP and DMS in marine algae. Nature 418:317-320 [doi:10.1038/nature00851].

Toda, K., and P. K. Dasgupta. 2008. New applications of chemiluminescence for selective gas analysis. Chem. Eng. Comm. 195:82-97 [doi:10.1080/00986440701569150].

Turner, S. M., G. Malin, P. S. Liss, D. S. Harbour, and P. M. Holligan. 1988. The seasonal-variation of dimethyl sulfide and dimethylsulfoniopropionate concentrations in nearshore waters. Limnol. Oceanogr. 33:364-375.

, G. Malin, P. D. Nightingale, and P. S. Liss. 1996. Seasonal variation of dimethyl sulphide in the North Sea and an assessment of fluxes to the atmosphere. Mar. Chem. 54:245-262.

Vallina, S. M., and R. Simó. 2007. Re-visiting the CLAW hypothesis. Environ. Chem. 4:383-387 [doi:10.1071/EN07055]. 
Velikova, V., F. Loreto, T. Tsonev, F. Brilli, and A. Edreva. 2006. Isoprene prevents the negative consequences of high temperature stress in Platanus orientalis leaves. Funct. Plant Biol. 33:931-940 [doi:10.1071/FP06058].

Westberg, H., B. Lamb, R. Hafer, A. Hills, P. Shepson, and C. Vogel. 2001. Measurement of isoprene fluxes at the PROPHET site. J. Geophys. Res. Atmos. 106:24347-24358 [doi:10.1029/2000JD900735].
Zimmer, W., and others. 2000. Process-based modelling of isoprene emission by oak leaves. Plant Cell Environ. 23:585595 [doi:10.1046/j.1365-3040.2000.00578.x].

Submitted 19 August 2009

Revised 29 January 2010

Accepted 16 March 2010 